Bioscientia Medicina: Journal of Biomedicine \& Translational Research

Journal Homepage: www.bioscmed.com

\title{
Maternal Death Cause by Antepartum Eclampsia, With HELPP Syndrome and AKI Stage
}

\section{III : A Preventable Recurrent Death}

\section{Ferry Yusrizal'1, Fitria Koeshardani ${ }^{1}$. Agustina $\mathbf{H}^{2}$, Zulkhair Ali ${ }^{3}$, Junaidi A $^{4}$}

${ }^{1}$ Department of Obstetric and Gynecology Faculty of Medicine Sriwijaya University / Dr. Moh. Hoesin Hospital, Palembang, Indonesia

${ }^{2}$ Department of Anaestesiology and Intensive Therapy Faculty of Medicine Sriwijaya University / Dr. Moh. Hoesin Hospital Palembang, Indonesia

${ }^{3}$ Department of Internal Medicine Faculty of Medicine Sriwijaya University / Dr. Moh. Hoesin Hospital, Palembang, Indonesia

${ }^{4}$ Department of Neurology Faculty of Medicine Sriwijaya University / Dr. Moh. Hoesin Hospital, Palembang, Indonesia

\section{A R T I C L E I N F O}

Keywords:

Eclampsia

HELLP syndrome

Maternal death.

\section{*Corresponding author: \\ Ferry Yusrizal \\ E-mail address: \\ ferry.yusrizal@gmail.com}

All authors have reviewed and approved the final version of the manuscript.

https://doi.org/10.32539/bsm.v5i11.372

\section{Introduction}

Preeclampsia (EPH-Gestosis) is a blood vessel endothelial disorder that causes vascular vasospasm leading to increased blood pressure. Preeclampsia is

\begin{abstract}
A B S T R A C T
Background: Eclampsia and severe preeclampsia is of the most frequent cause of maternal death. We usually find the case like this in our daily practice. The case most likely could be prevented. Eclampsia defined as a generalized seizure following preeclampsia in pregnancy. Eclampsia/Preeclampsia (EPH-Gestosis) cause a multisystem dysfunction such as HELLP syndrome, microangiopathy hemolytic anemia, liver dysfunction, and thrombocytopenia. Eclampsia and HELLP syndrome lead to maternal mortality, which happened mostly during third trimester.

Most of the patient came to the hospital in a bad condition where the multi organs failure were exist. EPH-Gestosis are due to maternal death in 43,75\%. Even the case usually severe, it's a preventable death. A proper strategy is needed to reduce or to avoid the maternal death. Objective: To analyse a maternal death with eclampsia and how to prevent this recurrent death. Case Report: A woman, 30 years old, G2P1A0 32 weeks pregnant not in labor with antepartum eclampsia was admitted to Mohammad Hoesin General Hospital (MHGH) Palembang, a referral case. Patient experienced generalized seizure six times before coming to MHGH which every seizure duration is less than five minutes and unconscious. On physical examination, patient was conscious, with blood pressure of $160 / 100 \mathrm{mmHg}$, pale, and cold extremities. By ultrasound examination, it showed 34 weeks pregnancy with single life fetus. Laboratory examination showed leukocytosis $(25.000 / \mathrm{mm} 3)$, thrombocytopenia $(58.000 / \mathrm{mm} 3)$, hyperbilirubinemia, elevated SGOT and SGPT (1691 and $861 \mathrm{U} / \mathrm{L})$, elevated creatinine serum $(2,46 \mathrm{mg} / \mathrm{dl})$, and elevated LDH (3629 $\mathrm{U} / \mathrm{L}$ ). The patient was treated based on the protocol for stabilization with intramuscular injection of $\mathrm{MgSO} 4$ 40\%, nifedipin $10 \mathrm{mg}$ per oral, intravenous injection of dexamethasone $12 \mathrm{mg}$, and plan to terminate the pregnancy by caesarean procedure. The male baby was born, $2000 \mathrm{~g}$ weight and APGAR score $4 / 6 / 8$. After the cesarean the consciousness not so well. Collaborating therapy to handle the case, with the anesthesiologist, internist and neurologist. Maternal death occurred in 3 days hospitalized ...caused by multi organ failure (MOF). Conclusion: The maternal death caused by antepartum eclampsia and the complication. The diagnosis of antepartum eclampsia and HELLP syndrome was decided based on history taking, physical examination, and supporting examination. Multiple organ failure exist in this case when the patient came to MHGH. Patient already treated and tried to overcome the complication but maternal death still occurred. This maternal death has a likely same story of previous death pattern. It is needed a strategy to prevent or to reduce the maternal death and how to make a good effort to cease the case become severe or worst.
\end{abstract}


complications, one of these is eclampsia and HELLP

syndrome. ${ }^{1}$ Eclampsia is a seizure that occurs due to decreased of organ blood perfusion caused by vasospasm during pregnancy. Eclampsia often occurs in the third trimester and the incidence increase when approaching term pregnancy. ${ }^{1}$ HELLP syndrome is a systemic disorder characterized by hemolytic microangiopathy anemia, elevated liver enzymes, and thrombocytopenia. ${ }^{1}$ HELLP syndrome can cause death due to liver rupture, disseminated intravascular coagulation, failure of the kidneys, acute pulmonary edema, thrombosis, and rupture of blood vessels. ${ }^{2,3}$

Our problem is how to prevent this maternal death. It is fact, this case is a preventable death. Unfortunately, we usually received the referral case in a worse condition, such as this eclampsia.

Indonesia of the countries that was not success in Millennium Development Goals (MDG's) to reach the target in reducing the maternal mortality. It's needed a big effort to reduce this maternal mortality. This is a recurrent death we usually find, and this could be avoided whenever we have a a good collaboration among the patients and the families and the health providers.

\section{Case Reports}

A woman, 30 years old, G2P2A0 32 weeks pregnant with complaint of seizure at home and come for help to the midwife before admitting to Siti Khodijah Hospital, and had five seizures before she was finally referred to Mohammad Hoesin General Hospital (MHGH). It's referred to MHGH due to full bed of the ICU facilities. The seizure duration was less than five minutes, after seizure the patient was unconscious. The patient had a history of high blood pressure during pregnancy from the age of 6 months. There is a history of high blood pressure the previous pregnant, no history of seizures in previous pregnancy. The patient received intramuscular injection of MgSO4, of nicardipine in D5\% $100 \mathrm{cc}$, intravenous ceftriaxone injection, $500 \mathrm{mg}$ of intravenous tranexamic acid, and $80 \mathrm{mg}$ of furosemide intravenously at Siti Khodijah Hospital.

On physical examinatio at $\mathrm{MHGH}$, the blood pressure of $160 / 100 \mathrm{mmHg}$. The patient appeared anemic and had cold extremities. By ultrasound examination, it was found 34 weeks of pregnancy, single life fetus (Figure 1). From laboratory result, there were leukocytosis $(25,000 / \mathrm{mm} 3)$, thrombocytopenia $(58,000 / \mathrm{mm} 3)$, hyperbilirubinemia, increased SGOT and SGPT (1691U/L and $861 \mathrm{U} / \mathrm{L})$, increased creatinine $(2.46 \mathrm{mg} / \mathrm{dl})$, and increased LDH ( 3629 $\mathrm{U} / \mathrm{L})$. The patient was diagnosed with G2P1A0 34 weeks of gestational age, not in labor, with antepartum eclampsia and HELLP syndrome, single live fetus, cephalic presentation. This patient was planned for abdominal termination / caesarean procedure after stabilization. The caesarean section result, the male baby weight 2000 grams and Apgar score 4/6/8.

The complication of EPH-Gestosis, such as HELLP syndrome, cerebrovascular disease, cardiac arrest, disseminated intravascular coagulation (DIC), respiratory distress syndrome, renal failure, sepsis, hepatic rupture, and hypoxic encephalopathy. This case was known to have complications of stage III acute renal failure, the urine output only $10 \mathrm{cc}$ in 6 hours. The $\mathrm{pH}$ value was 7.135 ; pCO2 27.4 ; pO2 110.1; Ht 28 ; Lactate 14.5, which meant that metabolic acidosis had also occurred. 

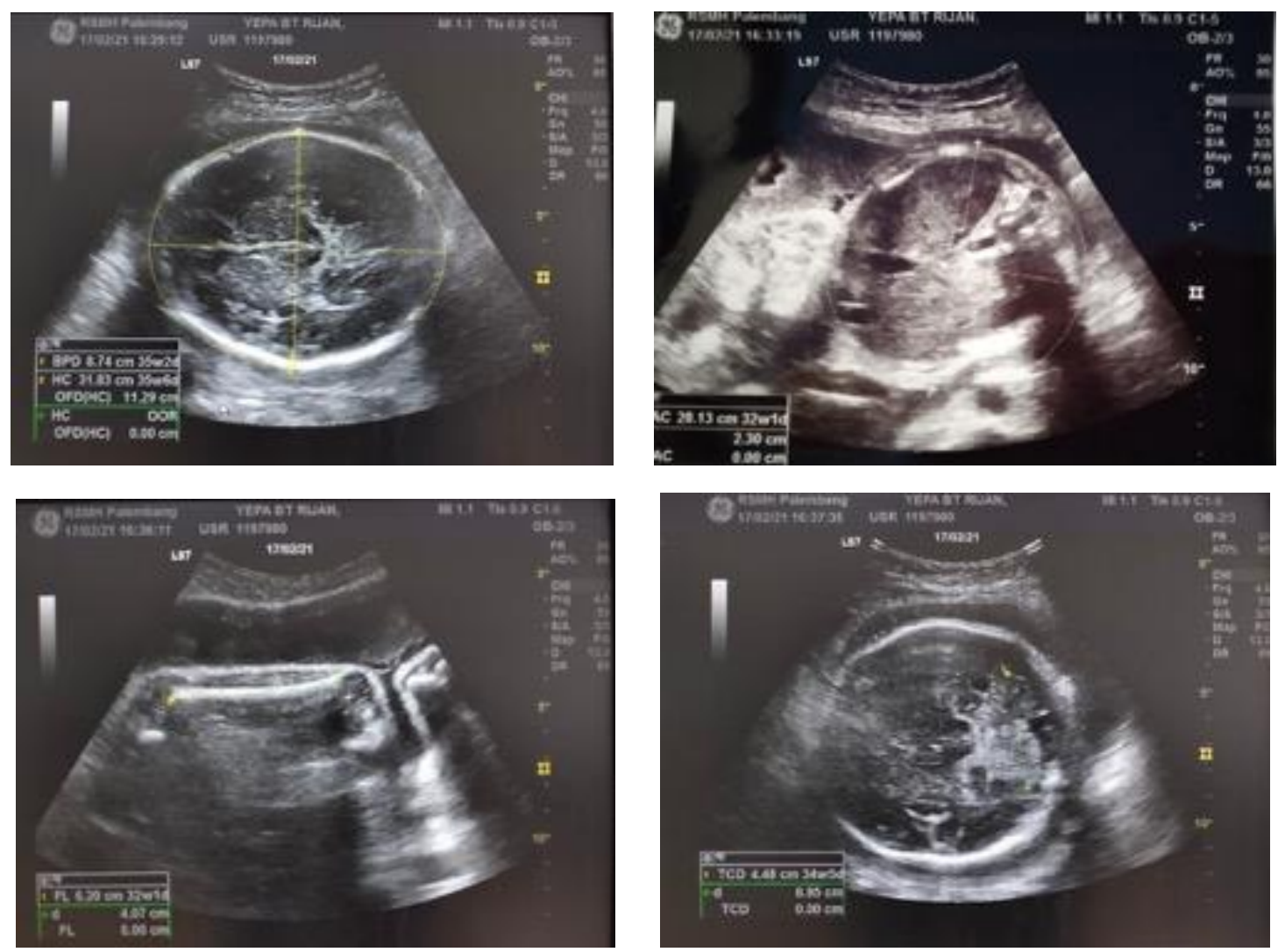

Figure 1. Ultrasound examination of 34 weeks gestational age with impression of a single life fetus, cephalic presentation

\section{Discussion}

Maternal death is an indicator to asses the quality of the health reproductive services in a country. Hypertension in pregnancy (EPH-Gestosis) is one of the main cause of maternal death. To prevent the EPGGestosis is a significant effort to reduce the maternal mortality.

Hypertension in pregnancy is defined by the International Society for the Study of Hypertension in Pregnancy (ISSHP) as hypertension $(\geq 140 \mathrm{mmHg}$ systolic or $\geq 90 \mathrm{mmHg}$ diastolic) with a new onset after
20 weeks of gestational age which occurs due to vasospasm of blood vessels, which can lead to hypertension in pregnancy. ${ }^{1}$ Preeclampsia is the cause of $15-20 \%$ of maternal mortality worldwide, as well as a major cause of fetal mortality and morbidity. 5 The etiology and pathophysiology of preeclampsia itself is not clearly known. However, it may be influenced by immunological maladaptation factors, genetic predisposition, and media-vascular factors. The following is a table of the diagnostic criteria for preeclampsia. ${ }^{1,6}$

Table 1. Diagnostic criteria for preeclampsia1,6

\begin{tabular}{ll}
\hline Blood pressure & Systolic $\geq 140 \mathrm{mmHg}$ or diastolic $\geq 90 \mathrm{mmHg}$ on 2 examinations \\
& with a minimum time span of 4 hours, after 20 weeks of \\
& gestation in women with previous normal blood pressure \\
& Systolic $\geq 160 \mathrm{mmHg}$ or diastolic $\geq 110 \mathrm{mmHg}$ can be \\
& confirmed at short intervals (minutes) \\
\hline and & Protein $\geq 300 \mathrm{mg} / 24$ hours total urine, or \\
\hline Proteinuria & Protein / creatinine ratio $\geq 0.3$
\end{tabular}


- Urine dipstick 1+ test (only used if quantitative methods are

not available)

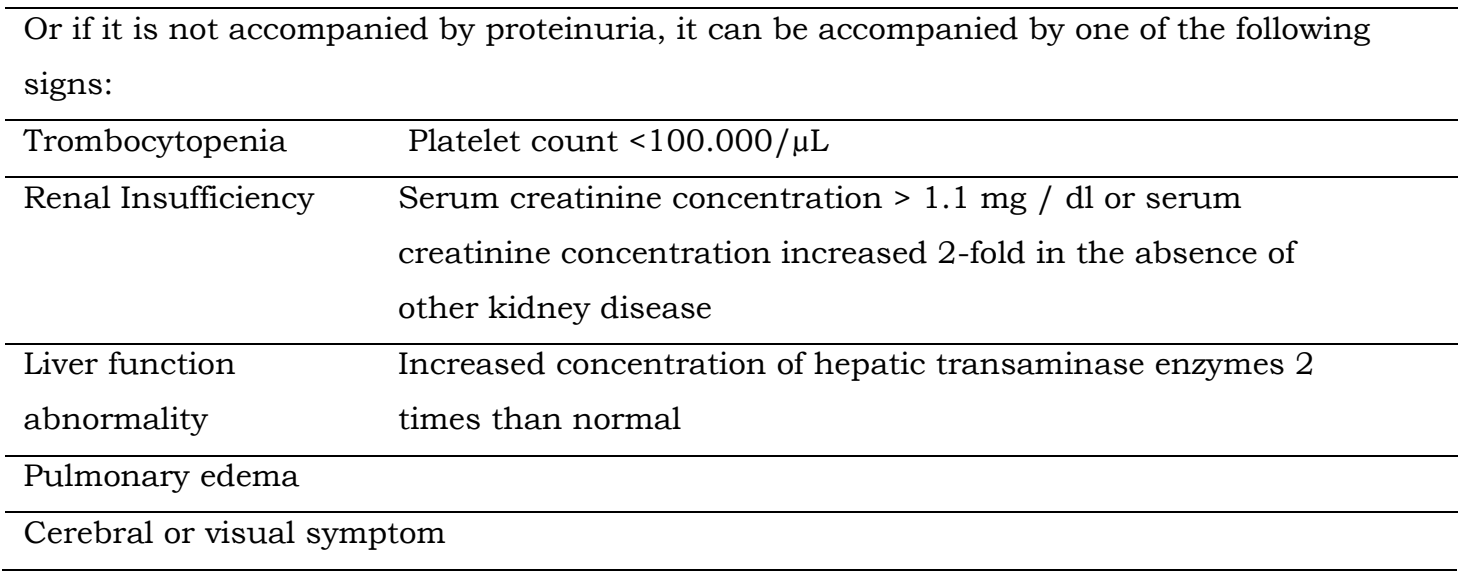

Common complications of preeclampsia include eclampsia (19\%), HELLP syndrome (2-20\%), pulmonary edema $(2-5 \%)$, acute renal failure (1-5\%), placental solutions (1-4\%), and fetal growth restriction (10-25\%). Eclampsia is a generalized seizure event or generalized seizure that can occur, either before, during, or after delivery. Eclampsia is always preceded by preeclampsia, which then causes a decrease in organ blood perfusion, where the initial process is preceded by vasospasm events.

HELLP syndrome is a systemic disorder characterized by microangiopathic hemolysis, impaired hepatic function, and thrombocytopenia. The pathophysiology of HELLP syndrome begins with damage to the endothelial cells of the spiral arteries, which causes hypoxia and leads to acute atherosis. Acute atherosis is characterized by discontinuity of vascular endothelial cells, focal disturbance of the basement membrane, platelet deposition, formation of mural thrombus, which then leads to fibrinoid necrosis. This acute atherosis is a pathognomonic sign of preeclampsia. All of these things cause circulation and coagulation disorders in pregnant women. Endothelial damage to the liver accompanied by platelet activation and aggregation will lead to increased platelet consumption. This process causes ischemia and hepatocyte cell death. $8,9,10$

The diagnosis of HELLP syndrome can be confirmed based on laboratory results, including 1 ) hemolysis $(\mathrm{H})$, namely hemolysis anemia characterized by Burr cells, schistocytes in peripheral blood images, an increase in indirect bilirubin, and an increase in lactate acid dehydrogenase ( $\mathrm{LDH}>600 \mathrm{U} / \mathrm{L})$; 2) elevated liver enzyme (EL: elevated liver enzyme), namely the damage to hepatocyte cells which causes an increase in aspartate aminotransferase (AS), ALT (alanine aminotransferase), bilirubin and LDH; 3) thrombocytopenia (LP: low platelets), which is characterized by a decrease in platelet count $<100,000 / \mathrm{mm}$. The main recommendation from RCOG (Royal College of Obstetric and Gynecology) regarding the management of HELLP syndrome is termination of pregnancy, either vaginal or vaginal. Abdominal termination was choosen when obstetric indications are present. Maternal death from HELLP syndrome is usually caused by complications, including cerebrovascular disease, cardiac arrest, disseminated intravascular coagulation (DIC), respiratory failure syndrome, kidney failure, sepsis, hepatic rupture, and hypoxic encephalopathy. ${ }^{2,3}$

Based on the case history, this case with hypertension who occurred during pregnancy, experienced seizures, a total of six times, duration $<5$ minutes, and after the seizure the patient was unconscious. The patient was treated according to eclampsia management guidelines, in the form of intramuscular MgSO4 (on the right and left buttocks) and drip of 1 vial nicardipine in D5\% $100 \mathrm{ml}$. The patient did have a history of hypertension in previous pregnancies. Examination revealed hypertension (blood pressure 160/100 $\mathrm{mmHg}$ ), conjunctival pallor, and cold extremities. Based on investigations, hemolysis, 
elevated SGOT and SGPT, and thrombocytopenia were found. The management of the patient is termination of the pregnancy. After birth, the patient underwent treatment in the ICU and then died 3 days after giving birth.

In this case, there was postpartum maternal death. The patient had six times of seizures and abdominal termination was done. In postpartum ICU the case to be cared with the collaboration of internist, anesthesiologist and neurologist. The patient developed respiratory failure and then used mechanical ventilator. It had complications in the form of stage III acute renal failure, as assessed by urine output (10 cc in 6 hours). Laboratory studies also reveal metabolic acidosis and, the death occurred due to multiple organ dysfunction syndrome (MODS) which arises as a result of complications of eclampsia and HELLP syndrome.

\section{Conclusion}

The cause of the patient's death in this case was multiple organ dysfunction syndrome due to complications of eclampsia and HELLP syndrome. When the MOF occuerd, death of MOF more than $60 \%$. Management of this case in this hospital was in accordance with the procedure and was carried out adequately.

\section{References}

1. Cunningham FG, Leveno KJ, Bloom SL, Hauth JC, Rause, Spong CY, et al. Hypertensive disorder in pregnancy. Williams Obstetrics. 25th ed. New York: McGraw-Hill, 2018: 101835.

2. Brown MA. Diagnosis and classification of preeklamsia, hypertensive disorders of pregnancy. 2003; In: Belfort M. A., Thornton S, Saade GR.

3. Rana S, Lemoine E, Granger JP, Karumanchi SA. Preeclampsia: Pathophysiology, challenges, and perspectives. Circ Res. 2019;124(7):1094-112.

4. Creasy RK, Resnik R, Lams JD, Lockwood CJ, Moore TR, Greene FM. Creasy \& Resniks's maternal-fetal medicine principles and practice. 7th ed. Philadelphia: Elsevier saunders; 2013.

5. Raghupathy R. Cytokines as key players in the pathophysiology of preeclampsia. Journal Medical Principles and Practice, 2013, 22 (23), 8-19.

6. American College of Obstetricians and Gynaecologists. Gestational hypertension and preeclampsia. ACOG Practice Bulletin No. 222. Obstet Gynecol. 2020;135:e238.

7. Barton JR. SIbai BM. Management of hypertensive crisis including stroke. Elsivier. 2011:101-13.

8. Mihu. Hellp syndrome-a multicenter disorder. J Gastrointestin Liver Dis. 2008.

9. Sibai BM, Stella CL. Diagnosis and management of atypical preeclampsiaeclampsia Am J Obstet Gynecol 2009;200:481.e1-481.e7.

10. Seifter JL. Integration of acid-base and electrolyte disorders. N Engl J Med. 2014;371(19):1821-31. 